D OT/FAA/AM -98/6

Office of Aviation Medicine

Washington, D.C. 20591

\section{An Evaluation of Pilot Acceptance of the Personal Minimums Training Program for Risk M anagement}

\author{
Richard S. Jensen \\ James E. Guilkey \\ The Ohio State University \\ Columbus, Ohio 43210 \\ David R. Hunter \\ Office of A viation Medicine \\ Federal Aviation Administration \\ Washington, DC 20591
}

February 1998

Final Report

This document is available to the public through the National Technical Information Service, Springfield, Virginia 22161.

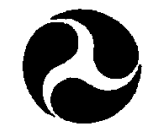

U.S. Department of Transportation

Federal Aviation Administration 


\section{NOTICE}

This document is disseminated under the sponsorship of the U.S. Department of Transportation in the interest of information exchange. The United States Government assumes no liability for the contents or use thereof. 
Technical Report Documentation Page

\begin{tabular}{|c|c|c|c|c|}
\hline $\begin{array}{l}\text { 1. Report No. } \\
\text { DOT/FAA/AM-98/6 }\end{array}$ & \multicolumn{2}{|c|}{ 2. Government Accession No. } & \multicolumn{2}{|c|}{ 3. Recipient's Catalog No. } \\
\hline \multicolumn{3}{|c|}{$\begin{array}{l}\text { 4. Title and Subtitle } \\
\text { An Evaluation of Pilot Acceptance of the Personal Minimums Training } \\
\text { Program for Risk Management }\end{array}$} & \multicolumn{2}{|c|}{$\begin{array}{l}\text { 5. Report Date } \\
\text { February } 1998\end{array}$} \\
\hline \multicolumn{3}{|c|}{$\begin{array}{l}\text { 7. Author(s) } \\
\text { Jensen, R.S., Guilkey, J.E., }{ }^{1} \text { and Hunter, D.R. }{ }^{2}\end{array}$} & \multicolumn{2}{|c|}{ 8. Performing Organization Report No. } \\
\hline \multicolumn{3}{|c|}{ 9. Performing Organization Name and Address } & \multicolumn{2}{|c|}{ 10. Work Unit No. (TRAIS) } \\
\hline $\begin{array}{l}{ }^{1} \text { The Ohio State University } \\
\text { Columbus, Ohio } 43210\end{array}$ & \multicolumn{2}{|c|}{$\begin{array}{l}{ }^{2} \text { Office of Aviation Medicine } \\
\text { Federal Aviation Administration } \\
\text { Washington, DC } 20591\end{array}$} & \multicolumn{2}{|c|}{$\begin{array}{l}\text { 11. Contract or Grant No. } \\
\text { DTFA 0l-92-10204 }\end{array}$} \\
\hline \multicolumn{3}{|c|}{ 12. Sponsoring Agency name and Address } & \multicolumn{2}{|c|}{ 13. Type of Report and Period Covered } \\
\hline \multicolumn{3}{|c|}{$\begin{array}{l}\text { Office of A viation M edicine } \\
\text { Federal Aviation Administration } \\
800 \text { Independence A ve., S.W. } \\
\text { Washington, DC } 20591\end{array}$} & \multicolumn{2}{|c|}{ 14. Sponsoring Agency Code } \\
\hline \multicolumn{5}{|c|}{ 15. Supplemental Notes } \\
\hline \multicolumn{5}{|c|}{$\begin{array}{l}\text { 16. Abstract } \\
\text { A new general aviation training program entitl } \\
\text { Pre-Take-off Decisions" was field tested in five } \\
\text { OH; Long Beach, CA; Anchorage, AL; Baltim } \\
\text { its acceptability to pilot audiences and to obtai } \\
\text { each case, following the presentation, participa } \\
\text { to the general aviation community. Analysis of } \\
\text { training program as helpful and intended to u } \\
\text { making in the future. Respondent comments an } \\
\text { sites resulted in progressive modifications t } \\
\text { acceptance and utility throughout the course of } \\
\text { with video and computer-based versions of this } \\
\text { conducted, possibly in concert with the dissemi } \\
\text { program. }\end{array}$} \\
\hline \multicolumn{2}{|c|}{$\begin{array}{l}\text { 17. Key Words } \\
\text { Aeronautical decision-making, Pilots, Pilot training, } \\
\text { Decision aids, Judgment, Decision making }\end{array}$} & \multicolumn{3}{|c|}{$\begin{array}{l}\text { 18. Distribution Statement } \\
\text { Document is available to the public through the } \\
\text { National Technical Information Service, } \\
\text { Springfield, Virginia } 22161\end{array}$} \\
\hline $\begin{array}{l}\text { 19. Security Classif. (of this report) } \\
\text { Unclassified }\end{array}$ & $\begin{array}{r}\text { 20. Security Classif. (of } \\
\text { Unc }\end{array}$ & & $\begin{array}{c}\text { 1. No. of Pages } \\
22\end{array}$ & 22. Price \\
\hline
\end{tabular}

Form DOT F 1700.7 (8-72)

Reproduction of completed page authorized 



\section{ACK N O W LEDGMENTS}

This program was sponsored by the Federal Aviation Administration and conducted under contract DTFA 0I-92-10204.

The authors thank Mr. Roger M. Baker, Jr., Manager, National Aviation Safety Program (AFS-810), Office of Flight Standards, for his assistance and support during this program.

The authors also thank Larry Kirkbride, who developed the original program, and Keith Hall, Ph.D., for his many vital contributions and for introducing the concept of "Engaged Learning" to this program.

The authors also thank the numerous unnamed pilots from across the United States for their invaluable suggestions and candid discussions. 



\section{TABLE OF CONTENTS}

BACKGROUND

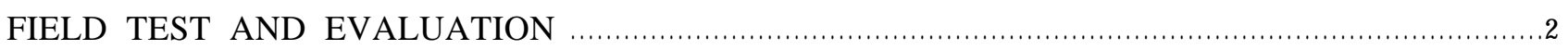

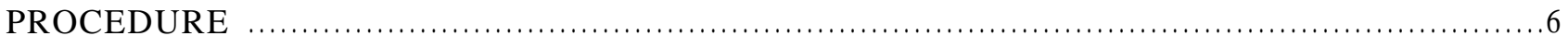

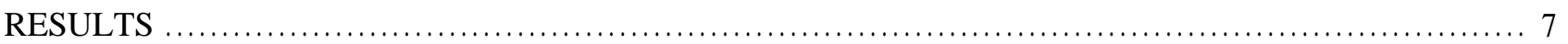

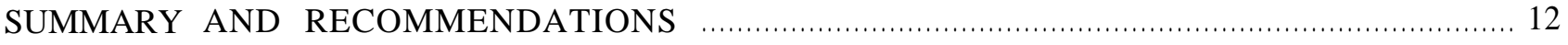

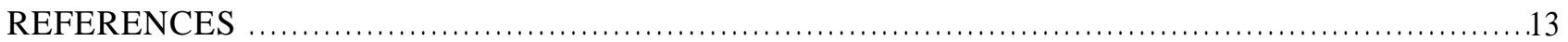

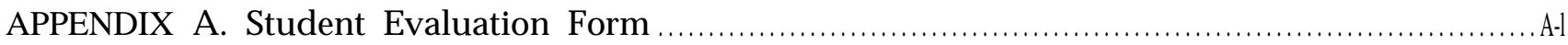

\section{LIST OF FIGURES}

Figure 1. Errors by pilots resulting in incidents

\section{LIST OF TABLES}

Table 1. Approximate attendance at personal minimums seminars.

Table 2. FAA certificates and ratings of responding participants .7

Table 3. Respondents' reactions to training program.

Table 4. Respondents' understanding of training materials.

Table 5. Learning experiences ranked "Best" by respondents

Table 6. Learning media ranked "Best" by respondents.

Table 7. Key implementation factors ranked "Best" by respondents 10

Table 8. Program length ranked "Best" by respondents. 



\section{A N Evaluation of Pilot Acceptance of the Personal Minimums \\ Training Program for Risk Management}

\section{BACKGROUND}

In a previous study, a preliminary training program was developed to help pilots develop personal minimums for risk management in pre-take-off go/ no-go decisions (Kirkbride, Jensen, Chubb, and Hunter, 1996). The purpose of the program was to give pilots an opportunity to make a commitment to follow selfdetermined guidelines for many decisions that they make regarding safety prior to the take-off decision. We believed that through such a commitment, pilots would be more likely to follow through than they would if the guidelines were developed and imposed by a regulatory agency. A viation safety is more dependent on pilots using judgment concerning their own capabilities to perform, given their circumstances, than it is upon pilots following regulations. This program was designed to help pilots develop that type of judgment.
The motivation for this research and intervention can be seen in the data presented in Figure 1. As shown in these data from the NASA ASRS program (McElhatton \& Drew, 1993), most errors that lead to incidents are made prior to the take-off. Of the 125 A viation Safety Reporting System (ASRS) incident reports reviewed in their study, $90 \%$ of all timerelated human errors occurred in the preflight or taxi-out phase of operation (e.g., the KLM crew who felt pressure to take-off before their "duty time" expired and crashed into another aircraft on a runway in Tenerife in 1977). Similarly, accidents are typically the result of a series of errors made by the flight crew, many of which are made prior to take-off.

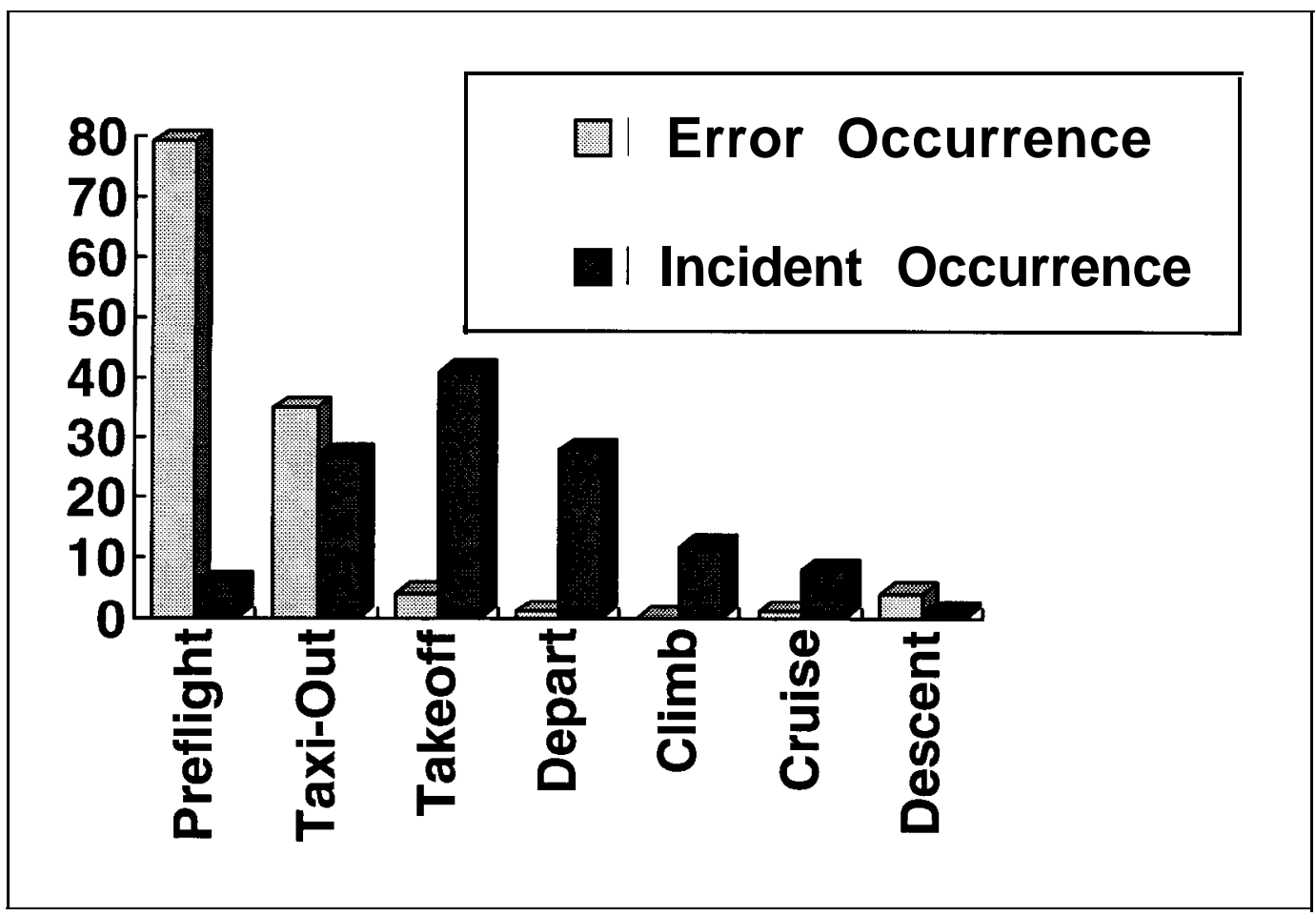

Figure 1. Errors made by pilots and their resulting incidents (McElhatton \& Drew, 1993). 
Incident and accident data such as these are not surprising. A flight is a sequence of events that are related and influenced by prior events. Once the commitment to flight is made, a strong psychological force exists in the pilot's mind to continue to the intended destination. Also, social or peer pressure may make admitting an error and turning around difficult or seemingly impossible. Furthermore, once airborne, certain options disappear, including the option to add more fuel. Pilots need to recognize the extent of the forces that will be applied to them once they make the decision to fly and factor them into their preflight go/ no-go decision, risk management is an important part of the overall task of flying airplanes.

All pilots recognize that there are risks in their flying activities and that some activities are riskier than others. Many pilots will not perform certain kinds of flying activities under certain circumstances but may do those same flying activities under other circumstances. For example, some pilots will fly a singleengine aircraft at night over mountains with a student in training who needs such experience but may be reluctant to do so with their own family (unless they have an important business meeting the next day at their destination). Although most pilots have not established guidelines for these types of decisions, they are, in fact, risk management decisions.

All of us can be pressured into taking risks by our circumstances. What causes you to take risks that you might not otherwise take? When you are in a long line of cars at a busy intersection, how long does the gap in traffic need to be before you will risk turning left across and into the traffic? Does the risk gap get shorter as you wait longer? If the driver behind you is honking? If you are in a hurry to catch a plane? If you have impatient passengers? We take risks in flight for many very legitimate reasons (e.g., transportation, convenience, economics). Sometimes, we make risky choices based on less legitimate reasons as well. After a close call, many people rationalize, "I had no choice, I had to do it." Safety in our aviation system depends, to a great extent, upon the amount of control we exercise over our choices to take risks.

In well established flying organizations, such as airlines and corporations, some of the risk management is governed by the establishment of clearly defined limits or minimums (Standard Operating
Procedures or SOPs) for flying activity. On the other hand, most general aviation pilots do not have a large organization that limits pilots' flying choices. Risk management for these pilots is left almost entirely to their discretion under the scrutiny of the FAA. In the area of preflight decision making, the Federal Aviation Regulations (FARs) state a pilot is to "become familiar with ALL available information concerning the flight" (FAR 91.103) and that the pilot is "directly responsible for" and "the final authority as to the operation of the aircraft" (FAR 91.3a). Furthermore, FAR 91.13 requires that the aircraft be operated in a way that it does not endanger the life or property of others. Nevertheless, in setting these limits, which are based upon the expected performance of fully competent pilots, the FAA still places most of the responsibility for risk management in the hands of the individual pilot Before each flight the individual pilot must determine whether his or her currency and aircraft meet this expected level of skill and capability. If these levels are not met, pilot judgment is expected to produce more conservative operational minimums for that situation. The training program described in this report is predicated upon the belief that appropriate personal minimums training can increase the awareness of the pilots to certain risks. Furthermore, individual pilot commitment to follow self-developed guidelines will increase the likelihood that there would be a reduction in pretake-off decisional errors and a corresponding improvement in safety.

\section{FIELD TEST AND EVALUATION}

In the present study, this new personal minimums training program was introduced and field tested in FAA seminars and other meetings across the USA. The primary objectives of the testing were to determine the acceptability of the training program to the general aviation community, to familiarize FAA Aviation Safety Program Managers with the training program, and to refine the program preparatory to delivery as a finished product suitable for distribution through the FAA safety training programs.

As field tested, the training program consists of five parts, 1) an introduction to the concepts of preflight decision making, risk management, and personal minimums, 2) the development of a list of 
risk factors in general aviation flying, 3) the assignment of risk factors to categories, 4) the establishment of personal minimum guidelines to shield against the risk factors, and 5) an evaluation of the established personal minimum guidelines. The program was usually completed within 90 minutes. The program was designed to engage the participants in the learning process through stimulating case studies, guided discussion, and individual and group activities. The program includes easily followed directions so that FAA Aviation Safety Program Managers (ASPM) can facilitate the program with only a brief training session. However, be cause of the nature of the training and the need for a commitment to behavior change in the participants, the program is best conducted by a facilitator who interacts well with the students. A copy of the program in Microsoft Power Point format is available from the sponsoring office.

Introduction to preflight decision making. In the first part of the program, students are given the basic concepts and motivated to learn and establish their own personal minimums through an examination of why preflight decisions are so important to flight safety. Preflight decisions are defined as: "Any and all decisions made prior to taxiing the airplane onto a runway with the intent to take off." In aircraft other than airplanes, preflight decisions are any and all decisions made prior to the first task to make the aircraft airborne (i.e., gliders-giving the initiate-launch signal; balloons-giving the command to launch; helicopters-advancing the throttle). Under this broad definition, preflight starts with the first idea to make a flight until the pilot initiates the first action to take the aircraft into the air or until that possibility no longer exists. This definition includes normal preflight decisions, but emphasizes the pilot's complete situation, including all of the assessments and commitments they make.

Personal minimums are defined as an individualized set of decision criteria (standards) to which the pilot is committed. Each pilot manifests a unique and variable set of skills and attitudes. Notwithstanding the well-recognized difficulties inherent in self-assessment, and in the absence of any other outside guidance, the individual pilot is the best judge of the risks involved in the contemplated flight. The psychological theory of cognitive dissonance (Festinger, 1957) suggests that, when they know they are not being watched, people are much more likely to follow standards that they have made themselves and announced (either publicly or in writing) than those imposed upon them by someone else. Therefore, the emphasis in this program is placed on getting pilots to commit to these "personal" minimums.

In contrast with imposed minimums (regulations or SOPs established by the FAA or one's organization), personal minimums are self-generated. We believe that, for the reasons noted above, in situations where no one is watching, a commitment will be stronger for personal minimums than it would be for imposed minimums. It is understood that, in most cases, personal minimums are (and will be) more conservative than the FARs. For example, the FAA regulations permit VFR with three miles visibility in any terrain and at night. There are many reasons why an individual might want to set his or her own minimums higher than three miles including: unfamiliarity with the area, scarcity of navigation points, towers, or hilly terrain. Each FAR could be considered similarly in applying one's own safety considerations to flying situations.

Flying is not unique as an enterprise of trust. In automobile driving, the actions of the driver are not observed by the police at every corner. Instead, the safety of the driver mostly depends upon voluntary compliance with the rules of the road and setting some personal standards depending on the situation. While some pilot operations take place under the direct supervision of regulators, management, supervisors, or others in authority, most flights in general aviation remain unsupervised.

In business aviation, commercial flight operations, and flying clubs, operational limitations or sets of rules define operational minimums. In these operations, pilots with less experience must operate with higher ceilings, higher approach minimums, lighter winds, and lower crosswind components. In airline and military operations, an extensive set of SOPs provides tools to assist pilots in making critical preflight go/ no-go decisions. Flights may be canceled by dispatchers, chief pilots, or supervisory personnel, even before the pilot has an opportunity to address the go/ no-go decision. Such supervision has proven to be effective in improving safety in these organizations. At least in part, this may be the reason for the very good safety record of these organizations. 
How can we apply the experience of these highly supervised operations to individual private pilot flying? Application of personal minimums offers an approach to improving risk assessment and management by self-supervision. Personal assignment of minimums requires an awareness of the risk factors involved before one can attempt to manage them. Furthermore, because some pilots may think that their responsibility ends with understanding their own safety risk, personal minimums training teaches them to acknowledge and consider the level of risk that is acceptable to passengers, the company, or others potentially affected by any flight consequences.

Following the introduction, participants should have the knowledge necessary to move into risk identification. In addition, they should be motivated to make risk assessment a priority for their own flying. Finally, they should have developed a level of comfort in sharing ideas with the facilitator and the rest of the group which will enable them to move on to discussing personal issues.

Risk factors. The second part of the training program is an individual activity in which the students are asked to generate and categorize a list of preflight risk factors. Research has shown that when people make decisions, they usually consider only a very small number of factors (Klein, 1993). The purpose of this activity is to expand the pilot's knowledge base of risk factors concerning preflight decision making and to classify them into categories that are easily recalled when needed. It is expected that better decisions will result from considering more risk factors and knowing how they interrelate. Risk awareness is an effective tool to increase safety but requires knowledge, experience, and a commitment to use one's knowledge.

Pilots are aware that flying is risky and that certain activities in flight are more hazardous than others. However, most pilots have not given much thought to the development of a risk management program for themselves. If they fly for a company, they may blindly follow the SOPs of that company without tailoring the program to fit their own knowledge, skills, and circumstances.

To stimulate thinking about risk factors and how they apply to preflight decisions, this section of the seminar offers one or more case studies in the form of "trigger tapes" of situations that are used to help participants understand the concepts and develop a set of risk factors often faced in preflight decisions. One excellent example was published in Flying Magazine's, “I learned about Flying From That" (McCutcheon, 1991). In this case, a pilot feels pressure to make a medical evacuation flight in a Cessna 210 with inoperative radios, in questionable weather, and with night approaching. After arriving for the passengers, he finds that in addition to the child and nurse that he had expected, there is also a mental patient to transport, along with a relative of the patient and other cargo, causing the plane to be overloaded. Despite the child's condition, because of the numerous risk factors, he decides not to take-off.

As students hear or read this story, they are asked to identify the risk factors facing the pilot including the subtle psychological factors such as the condition of the child or the desire to complete the job he was sent out to do. When all have listed these factors individually, the class is opened for discussion and all are invited to share their insights. The same could be done with any aviation preflight scenario, including those from individuals in the class, either in front of the whole class or in small groups.

After listing the risk factors, the students are to organize them into six suggested categories: pilot, aircraft, environment, operation/ mission, organization/ social, and miscellaneous. A form was provided for students to use as a checklist during this phase of the training. The first three categories are those normally used to represent the pilot's world. The operation/ mission category is added as a place to put factors regarding personal pressures to complete a mission. The organization/ social category is included as a place to put risk factors that organizations can add to the pilot's decision making process, including subtle pressures to complete flights on schedule. Finally, the miscellaneous category is included to underscore the emphasis on personal freedom in the construction of this tool, in anticipation that some may not wish to identify a particular risk factor with one of the given categories. The structure presented is offered as a starting point, not a required set of categories. What is placed under any category will be a function of each pilot's mental model of how these factors should be classified.

The students should have, by the end of the risk factor identification section, a list of risk factors for preflight decision making that includes both 
those seen in the videos and those each student has observed in their own. These risk factors are organized into categories including those less frequently used, such as the mission and sociological pressures.

Personal Minimum Guidelines. Personal minimum guidelines are simple acronyms, rules of thumb, sayings, if-then statements, forms, or memory aids representing what the pilot intends to do about the risk factors developed in the previous exercise. The development of these guidelines is more personal than the risk factor identification and should be done individually with direction from the facilitator and handout materials. In this activity, pilots begin to write their personal minimum guidelines, and will organize them into an easy-to-use checklist format. Some examples are offered to assist in getting started.

The same checklist form on which the pilots have written their risk factors is used to write their personal minimum guidelines regarding the risk factors that have been listed by categories. Pilots are encouraged to consider changes to the checklist that may better match their own ways of organizing the guidelines.

The personal minimum guidelines are the most important aspect of the program. Pilots are asked to write as many as they can think of for each category. They are encouraged to take the checklist home and add more guidelines as they come to mind. Some of these will be the result of talking with other pilots, while others will be the result of one's own experience. Changes to the guidelines can be expected as pilots become more experienced and as they lose recency of flying experience. It is suggested that changes to take greater risks should be made only after receiving formal training or currency. Changes to be more conservative should be considered during long periods of no flying.

In this section of the seminar, pilots are asked to share with each other the guidelines that they have established. This exercise usually results in a lively sharing session among the pilots. In this sharing, much of the real learning takes place. The facilitator only encourages the pilots to share and takes a minor role except to make a summary of some of the guidelines from time to time and, especially, at the end. Pilots are then encouraged to sign the checklist form indicating that on this day, they committed themselves to the personal minimums on their own checklist. This exercise can be highly rewarding because it offers opportunities for verbal expression and public commitment to safety. However, the instructor/ facilitator must be very sensitive to students who may not wish to share their ideas; some might consider them too personal to share.

After completing this section, participants should have a clear understanding of personal minimums and a set to which each has committed to follow. A side benefit of the exercise is that each will have reviewed the FAR requirements and thus will have a greater knowledge to take away from the seminar. From a teaching perspective, one can hardly do better than to learn rules by determining how they will be applied to one's own decisions.

Checklist Evaluation. The final part of the program is a review and evaluation of items included in each person's personal minimums checklist. Each participant should perform a self-evaluation of his or her personal checklist in the following way:

$\sqrt{ }$ Check for missing, unclear, and duplicate items.

$\sqrt{ }$ Consider the following general questions:

-Are the personal minimums flexible?

-Do they cover the range of intended flying activities?

-Do they address flying currency questions? -Do they cover the range of equipment and aircraft routinely used?

$\sqrt{ }$ Be sure they are written so that they will be understood at a later date.

$\sqrt{ }$ They should include a general statement about how the pilot will approach "non-routine" activities not covered by their set of minimums.

To avoid the possibility of embarrassment, the facilitator will offer a completed sample personal minimums checklist for students to discuss but not to use. Personal minimums are to be personal which means that they need to be determined by the person using them and not by the facilitator. Such samples of risk factors and guidelines should match the certification levels, flight activities, and other variables of the students in the class. Individual items on the checklist can be modified to reinforce guidelines from other pilot training efforts or to place particular emphasis on an issue of local concern to aviation safety. 
The instructor uses the discussion summary to reinforce the requirement for review and revision of the personal minimums checklist, and to check regularly one's checklist during biennial flight re views, instrument currency checks, safety program participation, or other recurrent training. A personal minimums checklist should be considered a flexible document that develops and changes with time and experience.

In closing, the facilitator reminds each pilot that the personal minimums checklist is unique to her or him. Other pilots' minimums will be different. The set of risk factors and checklist provided is never complete. They must be reviewed frequently and changed as required to accommodate the changing pilot activities and capabilities. To provide each pilot with further sources of information, they are referred to advisory circulars, magazines, books, newsletter (IFR Refresher, FAA Safety Review, etc.), and standard pilot references (Airman's Information Manual, FARs, etc.).

\section{PROCEDURE}

In the present study, the above described personal minimums training seminar was introduced and field tested in FAA seminars and other meetings across the USA. The primary objective of the field testing was to evaluate the acceptability of the training program to the general aviation community. This objective was addressed by gathering participant responses to multiple choice questions regarding: (1) the perceived utility of the program; (2) the intent of the participants to utilize personal minimums in the future; (3) the participants assessment of the clarity of presentation of the core concepts; and, (4) the participants preferences and opinions regarding training. Freeresponse questions also were used to solicit participant input regarding, for example, what they liked best and least about the program. The field test also provided an opportunity to familiarize FAA A viation Safety Program Managers (SPMs) with the training program, and to refine the program through modifications to the format and delivery as a result of comments received both from participants and from SPMs.

We must point out that, to a very large degree, the design and conduct of the study were dictated by the constraints of a field test environment. Specifically, by electing to evaluate the training program in the context in which it would eventually be utilized (viz. FAA safety seminars) the controls which might be present in a laboratory study were sacrificed. While we chose the locations of the field test sites so as to obtain a broad geographic representation of the United States, no such control was available over who elected to attend the safety seminars, which were simply advertised in the usual way. Neither could we demand that participants complete the post-training evaluation form, nor could we obtain rosters of participants for later follow-up. These sacrifices are certainly considerable, but we believe that the benefits obtained from obtaining the reactions of typical seminar participants in the settings in which the training is designed to be used justify that sacrifice.

Testing was first done by presenting the live program as described above to Ohio State University students and instructors as a part of their regular aviation classroom courses. Then the program was given to pilot groups in the Columbus, Ohio local area including the Columbus FSDO, which organized an audience of Part 135 operators, the WrightPatterson AFB flying club in Dayton, a chapter meeting of a local Civil Air Patrol, a local chapter meeting of Glassair builders and pilots, and a local flying club (Central Ohio Flyer's Association). Following each of these presentations changes were suggested and made to improve the training.

The program was then taken on the road to the EAA Convention at Oshkosh and to FAA FSDOs in Baltimore-Washington, Anchorage, Long Beach, and Chicago. Finally, it was presented in Washington at the FAA's Hanger 6 pilot safety meeting. The attendance at each of these seminars is shown below in Table 1. After each presentation, changes were made to improve the program, the student material, and the visual material. The final program shown in Appendix $A$ reflects the ideas and responses from participants in these seminars.

\section{Data Collection and Analysis}

At the completion of each seminar, participants were asked to immediately complete the evaluation sheet shown in the Appendix. The questions on this evaluation were designed to gather data on specific questions regarding how well the participants understood the concepts as well as how they felt about the program itself. We wanted to know if participants thought that the program would be 
Table 1. Approximate attendance at personal minimums seminars

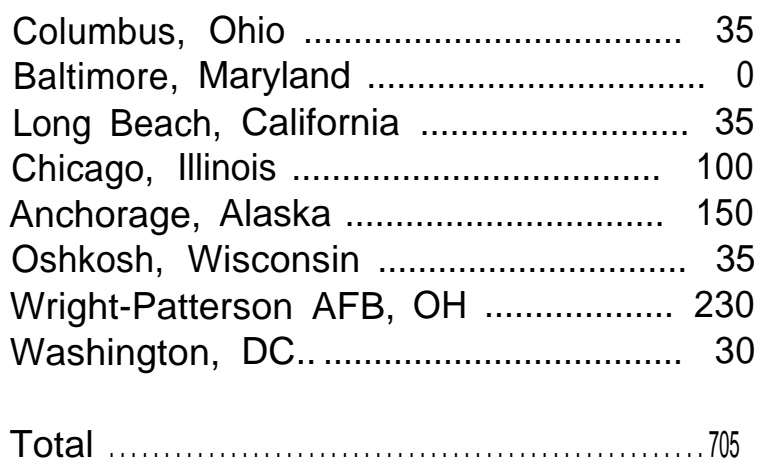

well received by the general aviation community and whether they would invite their friends to the program at a future date. We also wanted to know if they thought the program would affect their use of personal minimums in the future.

Although attempts were made to ease the burden of filling out the evaluation form following each seminar, it still appeared to be a tedious task for some participants. Many (about 75\%) participants did not do the evaluation task. However, 187 responses were received from the various field programs that provided useful data about the program.

The background of the respondents who filled out the evaluation form covered the spectrum of the general aviation community. Of the 187 respondents, 165 indicated that they had logged flight time. The mean flight time among the respondents who had logged flight time was 2,237 hours; 20 had between 5,000 and 10,000 hours; 5 had between 10,000 and 20,000 hours; and two had over 20,000 hours. Table 2 presents the number of seminar respondents who returned responses and indicated the pilot certificates and ratings that they hold.

The analysis of the data consisted of tabulating the responses to each of the questions that had a rating form and reviewing all of the comments.

\section{RESULTS}

As noted earlier, the primary objective of this study was to obtain participant reactions to the training program. Table 3 presents the responses of
Table 2. FAA certificates and ratings of responding participants

\begin{tabular}{lccc}
\hline & $\begin{array}{c}\text { Sample } \\
\text { N }\end{array}$ & $\begin{array}{c}\text { Sample } \\
\%\end{array}$ & $\begin{array}{c}\text { Population }^{2} \\
\%\end{array}$ \\
Student & 16 & $10 \%$ & $16 \%$ \\
Private & 66 & $40 \%$ & $41 \%$ \\
Commercial & 47 & $28 \%$ & $19 \%$ \\
ATP & 33 & $20 \%$ & $17 \%$ \\
& & & \\
CFI & 49 & $30 \%$ & $11 \%$ \\
Instrument & 36 & $22 \%$ & $46 \%$
\end{tabular}

Note 1: Percentages based upon the 165 respondents who reported having logged flight time. Note 2: Source FAA Statistical Handbook of Civil Airmen Statistics, 1993.

the respondents to the four multiple-choice questions which directly addressed this issue. Since pilots are unlikely to use any product which they do not consider to be of direct benefit to them, one simple index of the acceptability of the training program is the degree to which the program is perceived to be helpful. Eighty-five percent of the respondents indicated that they thought the program would be extremely helpful or helpful. An additional 13\% were neutral on that issue, and only $2 \%$ did not think that using personal minimums would be helpful.

The respondents' expressed intent to use personal minimums during their preflight decision making was addressed by the second multiplechoice question. Ninety-seven percent of the respondents indicated they definitely will or may use personal minimums in the future. In addition, $91 \%$ of the respondents indicated they would recommend this seminar to other pilots, and $85 \%$ of the respondents believed that the program would be positively received by other general aviation pilots.

Three multiple-choice questions were dedicated to obtaining an assessment of the clarity of the training materials and presentation. However, be cause the directions for these questions did not clearly specify the training materials as being under evaluation, the respondents may have interpreted these questions as assessing their own understanding of the training concepts. The results, 
Table 3. Respondents reactions to training program

Q1. To what degree will this program be helpful to you?

$\begin{array}{lrr} & N & \% \\ \text { Extremely Helpful } & 33 & 18 \\ \text { Helpful } & 125 & 67 \\ \text { Neutral } & 24 & 13 \\ \text { Not Helpful } & 4 & 2\end{array}$

Q2. Will you use Personal Minimums to assist in your pre-take-off decisions in the future?

$\begin{array}{lrr} & \mathrm{N} & \% \\ \text { Definitely } & 148 & 82 \\ \text { Maybe } & 27 & 15 \\ \text { Unsure } & 2 & 1 \\ \text { No } & 4 & 2\end{array}$

Q3. Would you recommend this seminar to other aviators?

$\begin{array}{lrr} & N & \% \\ \text { Yes } & 168 & 91 \\ \text { No } & 16 & 9\end{array}$

Q4. How do you think this program will be received by general aviation pilots?

$\begin{array}{lrr} & \mathrm{N} & \% \\ \text { Very Positive } & 40 & 22 \\ \text { Positive } & 117 & 63 \\ \text { Neutral } & 26 & 14 \\ \text { Negative } & 2 & 1 \\ \text { Very Negative } & 0 & 0\end{array}$


shown in Table 4, for these questions, then, are potentially confounded by two related, but distinct factors: first, the clarity of the materials related to the three core concepts; and, second, the respondents' perceived understanding of the concepts. Since the respondents' understanding of the concepts is probably (but not necessarily) attributable to some degree to the clarity of the presentation, the results may be interpreted as a general, but suspect, indication of the clarity of the materials and presentation. In this case the written responses to the open questions may be a better indicator of material and presentation quality.
Two questions on the evaluation form assessed the respondents' preferences for type of learning experience and presentation media. The small-groups category was the modal choice (49\%) for type of learning experience, while video and computer aided instruction were equally preferred as the learning medium (Tables 5 and 6). In Tables 5 through 8 the entry for each of the listed alternatives is the number of times that item was chosen as the most important (rank order $=1$ ). When asked to rank the key factors (shown in Table 7) to successful implementation of this training program, $33 \%$ of the respondents ranked applicability as the most important factor, followed

Table 4. Respondents' understanding of training materials

Q5a. Please indicate your level of understanding of :

Personal Minimums.

$\begin{array}{lrr} & \mathrm{N} & \% \\ \text { Easily Understood } & 170 & 93 \\ \text { Somewhat Understood } & 12 & 7 \\ \text { Unsure } & 1 & 0 \\ \text { Somewhat Confusing } & 0 & 0 \\ \text { Very Confusing } & 0 & 0\end{array}$

Q5b. Please indicate your level of understanding of:

Risk Factors

$\begin{array}{lrr} & \mathrm{N} & \% \\ \text { Easily Understood } & 158 & 86 \\ \text { Somewhat Understood } & 22 & 12 \\ \text { Unsure } & 3 & 2 \\ \text { Somewhat Confusing } & 0 & 0 \\ \text { Very Confusing } & 0 & 0\end{array}$

Q5c. Please indicate your level of understanding of:

Developing Guidelines.

\begin{tabular}{lrr} 
& $\mathrm{N}$ & $\%$ \\
Easily Understood & 119 & 66 \\
Somewhat Understood & 45 & 25 \\
Unsure & 11 & 6 \\
Somewhat Confusing & 5 & 3 \\
Very Confusing & 0 & 0 \\
\hline
\end{tabular}


Table 5. Learning experiences ranked "Best" by respondents

\begin{tabular}{lrr}
\hline & N & $\%$ \\
Lecture & 49 & 29 \\
Small Groups & 83 & 49 \\
Guided Discussion & 39 & 23 \\
Other & 0 & 0 \\
Total & 171 & \\
& & \\
\hline
\end{tabular}

Table 6. Learning media ranked "Best" by respondents

\begin{tabular}{lrc}
\hline & $\mathbf{N}$ & $\%$ \\
Overheads & 25 & 16 \\
Slides & 18 & 11 \\
Video & 56 & 35 \\
Computer Aided & 59 & 37 \\
Instruction \\
Other & 1 & 1 \\
Total & & \\
\hline
\end{tabular}

Table 7. Key implementation factors ranked "Best" by respondents

\begin{tabular}{lrr}
\hline & N & $\%$ \\
Applicability & 53 & 33 \\
Realism & 42 & 26 \\
Accuracy & 14 & 9 \\
Meaningfulness & 52 & 32 \\
Other & 1 & 1 \\
Total & 162 & \\
& & \\
\hline
\end{tabular}


closely by meaningfulness (32\%). Finally, the modal choice for optimal program length was 60 minutes (Table 8).

Five open-ended questions allowed the respondents to provide input not constrained by the multiple-choice format. In addition to three questions dealing specifically with the training seminar, two questions were included that solicited general information regarding the respondents' personal flying experiences and their opinions on how this program might be applied specifically to them. The specific questions and a few responses, chosen to represent the typical content, are given below.

\section{Q uestion 10: "W hat do you see as the most impor- tant component of this seminar?"}

$\sqrt{ }$ Makes you reconsider your personal minimums.

$\sqrt{ }$ Determining those few "inviolate" factors and establish a go/ no-go point for those factors making people aware that they are already (probably) using personal minimums. This program just formalizes the process.

$\sqrt{ }$ By having a checklist, irrespective of its dynamic nature, forces you to look at each item. keeps you from overlooking something.

$\sqrt{ }$ Decision making awareness training.
Question 11: "W hat did you Like best about the seminar?"

$\sqrt{ }$ Review risks, develop idea, then help review how to develop guidelines.

$\sqrt{ }$ To get people to think about their personal minimums as opposed to talkingvaguely about judgment.

$\sqrt{ }$ Preparation of your own personal minimum checklist.

$\sqrt{ }$ Stressing self-development and ownership.

$\sqrt{ }$ The guided discussion without it feeling like an exam.

$\sqrt{ }$ Relevance, get me started thinking about formalizing a checklist for myself.

$\sqrt{ }$ Everyone opening up about things they've learned the hard way.

$\sqrt{ }$ Group Discussion \& personal experiences.

Question 12: "What did you dislike about the seminar?"

$\sqrt{ }$ Could be seen as yet another regulation.

$\sqrt{ }$ Too simplistic, overly basic, covers too many obvious items. experienced pilots should long ago have developed their own minimums.

$\sqrt{ }$ The hanger was a lousy environment-bad acoustics, couldn't see the screen, noisy birds, etc.

$\sqrt{ }$ Group was probably too large for fully exploring ideas presented.

$\sqrt{ }$ Too little time to fill out this form and personal minimums from discussion.

$\sqrt{ }$ Was too short. I was looking forward to hearing more statistics as to what types of activities lead pilots into incidents and accidents.

Table 8. Program length ranked "Best" by respondents

$\begin{array}{lrr} & \mathbf{N} & \% \\ 30 \text { minutes } & 18 & 11 \\ 45 \text { minutes } & 30 & 18 \\ 60 \text { minutes } & 68 & 40 \\ 90 \text { minutes } & 54 & 32 \\ \text { Other } & 1 & 1\end{array}$

Total

171 
$Q$ uestion 13: "As you now know, true aviation stories about hazards that have been encountered are important to this program. Can you offer a story from your flying experience, that other pilots should know about to increase their ability to make safe decisions?"

$\sqrt{ }$ Yesterday I was very tempted to put wheels down on a very turbulent small runway because a student aborted in front of me and an experienced pilot was behind me. All three of us aborted the landing.

$\sqrt{ }$ One of my guidelines is to read back everything given to me by a controller; that has solved a lot of potential problems. Along with "reading back" information to controllers make sure to talk or question them whenever you are unsure about anything. Now for my story! I was cleared to take off from the parking ramp at a control tower field when I requested a taxi clearance. I read the clearance back to the tower which did not respond. So I taxied out to the runway and was about to roll across the hold short line when I had a funny feeling. I then stopped and radioed the tower that I was assuming the active, It turned out that they did not intend for me to take the active.

$\sqrt{ }$ Too many; IFR instruction cross-country in IMC. After turn on ILS, we were given a hold for an inbound emergency aircraft with no NAV radios. The aircraft was a Citation with just bad radios installed which the crew neglected to check out and took off with minimum fuel. They got a radar approach into $700-\mathrm{L}$. We then got an ILS and landed.

$\sqrt{ }$ I'm a student pilot, recently I was doing closed pattern solo work at Manassas. Visibility deteriorated and there were several others, all doing same pattern work, when 3 other aircraft joined pattern I landed after deciding it was too busy for my skill level given the diminishing visibility.

Q uestion 14: "This program has been designed to provide general aviation pilots with a structured method to develop their own personal minimums. Will such a program be helpful in assuring your ow $n$ personal safety? If yes, bow will it help you? If no, why not?"

$\sqrt{ }$ I already do a similar procedure, albeit not as explicitly in my own go/ no go and decision making. As a CFI, I attempt to instill it in my students. $\sqrt{ }$ I have used [Personal Minimums] for a long time but not so much on personal levels, may rethink areas from GA standpoint.

$\sqrt{ }$ Suggest computer aided instruction that allows a final [summary] and a session that establishes a printed profile when complete.

$\sqrt{ }$ Not really - I already have had personal minimums for a very long time; most of the pilots I know have them as well.

\section{SUMMARY AND RECOMMENDATIONS}

This report has described a preliminary evaluation of a personal minimums training program conducted in a field setting. The training program was conducted in most cases as part of a normally scheduled FAA safety seminar and was approximately two hours in length. At the conclusion of the training program the participants were asked to complete a brief evaluation of the training program, consisting of both multiple-choice and openended questions. Approximately $25 \%$ of the seminar participants completed the evaluation form. This sample replicates the distribution of private pilots in the population (almost half of seminar participants), but underrepresents student pilots, while overrepresenting commercial pilots and certified flight instructors. Seminar locations were chosen so as to broadly represent different regions of the United States. These samples, therefore, represent samples of convenience and should be considered as such when assessing the generalizability of these results.

Subject to the limitations on generalizability noted above, the respondents' responses demonstrate that those pilots who receive the training believe that personal minimums training is helpful and that they will use it in the future in their preflight decision making. Further, they would recommend personal minimums training to other pilots and believe that it would be well received. Respondents also indicated that the core concepts of the training program were understood. These findings were noted both in the multiple-choice questions and in the respondents' responses to the open-ended questions.

These results are interpreted as providing support to the continued development of the personal minimums training program using both video and 
computer-aided instruction formats. It is important to note, however, that this field test did not evaluate the training effectiveness of this program. Although pilot acceptance of the program may well be essential for its implementation and use, acceptance does not imply effectiveness. While we believe that the concepts of a priori risk assessment and proceduralization of the decision making process have the potential to reduce pilot risk and improve safety, this limited study did not address that supposition.

As a follow on, we recommended that studies be conducted that assess the degree to which training on the use of personal minimums results in both the use of this tool in flight planning (as contrasted with the intent to use the tool, as assessed in the current study) and in changes in pilot behavior which result in better risk management, as evidenced, for example, by adherence to more conservative operational minimums or in lowered incidences of high risk activities. Such studies might utilize the semi-controlled approach such as that used by Buch (1984) and Diehl and Lester (1987) in their validation of a pilot judgment training program. An alternative and perhaps more feasible approach is to employ a field-oriented approach in concert with the fielding of the training program, in which rosters of training participants are developed and they are tracked over a number of years to assess differential incident and accident rates. Other approaches are also possible, but whatever the choice of study design the validation of training impact is a non-trivial matter that will require a substantial investment of effort, time, and resources. Even so, the benefit of such studies is substantial as they provide a means of estimating the impact, and hence the cost-benefit, of the training program.

Finally, let us note that, typically, behavioral change does not happen as a result of attending one seminar. Therefore, just as the airline industry has found in CRM, it is important to continue to offer variations of personal minimums training repeatedly to the same pilots. These variations could take the form of different scenarios in a classroom format, videos, computer-based-training, or internet formats. Refresher training is a central concept in aviation that recognizes the fleeting nature of human knowledge and skill, and is a concept that certainly should not be ignored here.

\section{REFERENCES}

Buch, G. (1984) A n investigation of the effectiveness of pilot judgment training. Human Factors, 26,55764.

Diehl, A.E., \& Lester, L.F. (1987). Private pilot judgment training in flight school settings. DOT/FAA/ AM-87/ 6. Washington, DC: Federal Aviation Administration, Office of Aviation Medicine. Available from: National Technical Information Service, Springfield, VA 22161. Order \# ADA 209327.

Festinger, L. (1957). A theory of cognitive dissonance. Evanstan, IL: Row, Peterson.

Klein, G.A. (1993). A recognition-primed decision (RPD) model of rapid decision making. In: G.A. Klein, J. Orasanu, R. Caldewood, and C.E. Zsambok, Decision making in action: Models and methods. Norwood, NJ: Ablex Publishing Corporation.

Kirkbride, L.A, Jensen, R.S., Chubb, G.P., \& Hunter, D.R. (1996). Developing the personal minimums tool for managing risk during preflight go/no-go decisions. DOT/ FAA/ AM-96/ 19. Washington, DC: Federal Aviation Administration, Office of Aviation Medicine. Available from: National Technical Information Service, Springfield, VA 22161. Order \#ADA 313639.

McCutcheon, D. (1991). I learned about flying from that: Better late than never. Flying Magazine, May 1991, pages 118-9.

McElhatton, J. \& Drew, C. (1993). Time pressure as a causal factor in aviation safety incidents: The "hurry-up" syndrome. In: R.S. Jensen \& D. Neumeister (eds.), Proceedings of the Seventh International Symposium on Aviation Psychology (pp. 269-74). Columbus, $\mathrm{OH}$ : The Ohio State University. 



\section{APPENDIX A}

PERSONAL MINIMUMS COURSE EVALUATION FORM 



\section{Personal Minimums Seminar Evaluation}

Thank you for participating in this experimental OSU/FAA Personal Minimums Seminar. We consider your insight to be highly important to the development of the finished program. The following questions are designed to help you communicate your ideas to us regarding how we can make this the best general aviation safety program that it can be. Please give us your ideas by answering the following questions. Feel free to add other comments as well.

1. To what degree will this program be helpful to you? (check one)

$\begin{array}{lc} & \text { Extremely Helpful } \\ -- & \text { Helpful } \\ -- & \text { Neutral } \\ -- & \text { Not Helpful } \\ -- & \text { Contradictory }\end{array}$

2. Will you use Personal Minimums to assist in your pre-take-off decisions in the future? (check one)

$$
\begin{array}{ll}
-- & \text { Definitely } \\
-- & \text { Maybe } \\
-- & \text { Unsure } \\
-- & \text { No } \\
& \text { Yes } \\
- & \text { No } \\
- & \\
- & \text { Very Positive } \\
-- & \text { Positive } \\
-- & \text { Neutral } \\
- & \text { Negative } \\
- & \text { Very Negative }
\end{array}
$$

\begin{tabular}{|c|c|c|c|}
\hline & Personal Minimums & Risk Factors & Developing Guidelines \\
\hline Easily understood & -- & -- & -- \\
\hline Somewhat understood & -- & $\ldots$ & -- \\
\hline Unsure & $\cdots$ & $-\cdots$ & $-\cdots$ \\
\hline Somewhat confusing & - & $-\cdots$ & $-\cdots$ \\
\hline Very Confusing & $\ldots$ & $\ldots$ & $\ldots$ \\
\hline
\end{tabular}

3. Would you recommend this seminar to other aviators?

4. How do you think this program will be received by general aviation pilots?

5. Please indicate your level of understanding of each of the following (check one box for each topic):

6. Please rank order what you believe to be the optimum length for this program. (I= best; 4=worst)

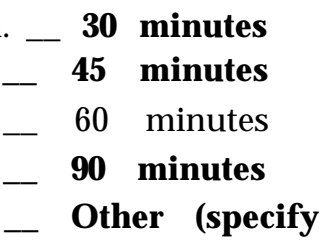


7. Please rank order the type of learning experience that best suits you. (1 =best; 4=worst)

8. Please rank order the type of learning medium that best suits you. (1 =best; $5=$ worst)

9. Please rank order what you believe to be the key factors to successful implementation of this program (I=best; $5=$ worst).

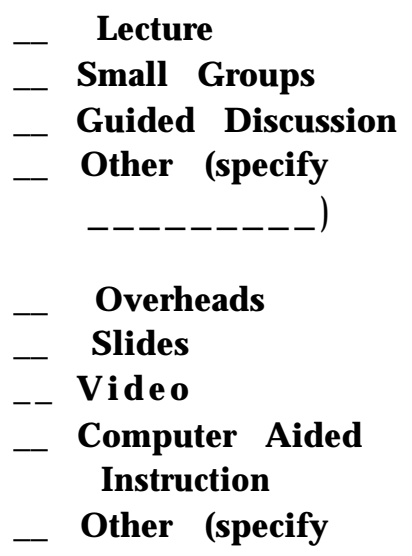

$-$

10. What do you see as the most important component of this seminar?

11. What did you like best about the seminar?

12. What did you dislike about the seminar?

13. As you now know, true aviation stories about hazards that have been encountered are important to this program. Can you offer a story from your flying experience, that other pilots should know about to increase their ability to make safe decisions?

14. This program has been designed to provide general aviation pilots with a structured method to develop their own personal minimums. Will such a program be helpful in assuring your own personal safety? If yes, how will it help you? If no, why not? 
15. Biographical information. In order for us to evaluate how this training is being used we would like to be able to contact you in a few months to see if you are using the information. This would just be a one or two page survey like the one you just completed and would greatly help us in evaluating this program. If you would consider taking part in that evaluation, please provide your name and address below so that we may contact you.

A ge : -..-.- Educational Level: High School Name:

$\begin{array}{lll}\text { Female: } & & \\ \text { Male: } & -- & \text { College } \\ & - & \text { Post-Graduate }\end{array}$

Phone:

e-mail:

Flight Experience:

Total Number of Hours:

Certificate/ Ratings Held:

If you are unable to complete this form here at the seminar, please do so at home and return it to: OSU Aviation Research, 164 W. 19th Ave, Columbus, OH 43210. Thank you for participating with us in this general aviation training development effort. 